Brit. F. vener. Dis. (1970) 46, 454

\title{
Kanamycin in the treatment of rectal gonorrhoea
}

\author{
J. L. FLUKER \\ Charing Cross Hospital Group
}

AND A. BOULTON HEWITT

Royal Northern Hospital-formerly Charing Cross Hospital Group

The rate of treatment failure in cases of rectal gonorrhoea has been the source of considerable concern in recent years and it was therefore decided to investigate the value of kanamycin for this condition.

As pointed out by Jefferiss (1966), the true incidence of gonorrhoea in passive homosexuals is undoubtedly greater than the figures of proven infections would suggest, as there are many cases in which the diagnosis is strongly suspected on historical or clinical grounds but bacteriological proof is lacking. In view of the fact that diagnosis may be difficult, it is all the more important that the treatment of those cases which are identified should be as efficient as possible.

The treatment of rectal infections with gonorrhoea by means of penicillin carries with it a much greater risk of failure than the use of corresponding doses of penicillin in urethral infections.

Using a dosage of 600,000 units of procaine penicillin, Scott and Stone (1966) reported thirteen (43 per cent.) cases of treatment failure in 36 patients treated and Evans (1966) reported seventeen (20.5 per cent.) in 83 patients. These figures suggest that either a considerably larger dosage of penicillin should be used to treat rectal gonorrhoea or an alternative drug should be used.

In general, treatment schedules which are relatively short and can be administered under the surveillance of the clinic staff are desirable. Homosexuals, particularly, need to be encouraged to attend a clinic in the first instance (Fluker, 1966) and it is doubly desirable that the treatment schedules employed for them should cause as little distress as possible. The necessity for administering the therapy under supervision is made obvious by the findings of Anderson (1966), who showed that over 30 per cent. of a series of patients attending a Venereal Disease Clinic had misused tablets given for a previous infection or had taken tablets prescribed for a sexual partner. For this reason, treatment by means of an injection is clearly preferable.
A single intramuscular injection of kanamycin appeared to offer a reasonably safe and effective alternative to penicillin in the treatment of rectal gonorrhoea.

\section{Kanamycin}

This antibiotic is closely related to streptomycin first isolated in 1957 and is particularly effective against Gram-negative organisms. It has the advantage over streptomycin that resistant organisms are slow to appear. The drug is relatively non-toxic but, as with streptomycin, ototoxicity (involving the cochlea) has been recorded and the risk is much enhanced if there is impairment of renal function (Finegold, 1959). The drug should be avoided if there is either history or present evidence of renal disease or hearing impairment or if the patient is over the age of 45 years. It is suggested that the patient be told that he has received an injection of kanamycin and that the total amount of kanamycin administered during a patient's lifetime should not exceed 40 g. - or in non-lethal conditions like gonorrhoea $20 \mathrm{~g}$.

AUDIOGRAMS were carried out after treatment in four patients, the results being within normal limits:

(1) Patient 3711 . United Kingdom born, 36 years of age. Right ear: Air conduction: Normal, except -10 per cent. at 500 c.p.s.

Bone conduction: Normal, except -10 per cent. at 2,000 c.p.s.

Left ear: Air conduction: -7 per cent at 500 c.p.s., -15 per cent. at 6,000 c.p.s.

Bone conduction: -10 per cent. at 2,000 c.p.s.

(2) Patient 1495. United Kingdom born, 27 years of age.

Right ear: Air conduction: -10 per cent. at 250,500 , $1,000,2,000$ and 4,000 c.p.s.

Bone conduction: +10 per cent. at 1,000 c.p.s.

Left ear: Air conduction: -10 per cent. at 250, -15 per cent. at 500 , and -10 per cent. at 1,000 to 8,000 c.p.s.

Bone conduction: -5 per cent. at $500,+10$ per cent. at 1,000 , and +5 per cent. at 2,000 c.p.s. 
(3) Patient 4608. West Indian, 30 years of age.

Right ear: Air conduction: Normal

Bone conduction: -5 per cent. at 250 to 4,000 c.p.s.

Left ear: Air conduction: Normal

Bone conduction: -15 per cent. at 250 , -5 per cent. at 1,000 , and -10 per cent. at 2,000 c.p.s.

(4) Patient 2800. Polish, 28 years of age.

Right ear: Air conduction: -70 per cent. at 4,000 , and -60 per cent. at 8,000 c.p.s.

Bone conduction: Normal

Left ear: Air conduction: -20 per cent. at 2,000, and -15 per cent. at 4,000 c.p.s.

(c.p.s. $=$ cycles per second). Where no figures are given the results are normal.

Apart from one patient who developed a transient rash on the buttock around the injection site, no toxic effects were observed.

\section{Method}

Patients with gonococcal proctitis were treated either with procaine penicillin 1.8 megaunits or with a single intramuscular injection of $2 \mathrm{~g}$. kanamycin. This dosage was chosen as it appeared from the work of Piguet (1961) that a dose of $1 \mathrm{~g}$. might be expected to have a rather high failure rate.

The diagnosis of gonococcal proctitis was made by the finding of typical Gram-negative diplococci in pus cells present in rectal smears. After treatment with either procaine penicillin or kanamycin, the patients were instructed to return between 1 and 4 days later when a further proctoscopic examination was carried out and repeat rectal smears stained by Gram's method were scrutinized for the presence of gonococci. Thereafter the patient was examined at weekly intervals. Serum tests for syphilis were performed at the first visit and repeated a month later.

PROCAINE PENICILLIN 1.8 MEGAUNITS:

The series consisted of 100 cases which occurred in ninety patients; one Australian, one West Indian, and one United Kingdom-born subject each had three infections and four United Kingdom-born subjects had two each. Their ages ranged from 16 to 43 years (mean 30). 75 were born in the United Kingdom, four in the United States of America, three in Cyprus, two in Australia, and one each in South Africa, Jugoslavia, Germany, Hungary, Portugal, and the West Indies. 84 were single, two married, two divorced, and one separated, and the remaining patient was a widower. $38(42 \cdot 2$ per cent.) gave a history of previous venereal disease.

\section{Results}

96 were followed and treatment failure was seen in 26 (27.1 per cent.).

Treatment failure as defined by Dallas (1958) was deemed to have occurred if gonococci were found in the smears between 1 and 14 days after treatment, there being no history of subsequent exposure to risk of infection.

KANAMYCIN $2 \mathrm{~g}$.

The series consisted of 100 cases which occurred in 96 patients; four United Kingdom-born subjects each had two attacks. Their ages ranged from 16 to 51 years (mean 27.1). 89 were born in the United Kingdom, one in Spain, one in New Zealand, one in Australia, one in India, one in the West Indies, one in Poland, and one in Switzerland. 86 were single, six married, one divorced, two separated, and the marital status of one was unknown. 48 (50 per cent.) gave a history of previous venereal disease.

Results

Ninety were followed and treatment failure was seen in fourteen ( 15.5 per cent.).

\section{Comment}

On account of the extraordinarily low default rate in the series treated with procaine penicillin, the epidemiological control achieved by both treatment regimes is similar, the percentage of possibly-infected defaulters being $1 \cdot 1$ for the penicillin series and 1.6 for the kanamycin series (Hewitt, 1969). Nevertheless, a failure rate with penicillin of almost 30 per cent. is clearly most unsatisfactory and the kanamycin regime is therefore preferable.

It was felt that the failure rate with kanamycin was somewhat higher than expected and that the success rate of the treatment should approximate to the success rate observed in female patients, a figure of 96.4 per cent. having been found by Hooton and Nicol (1967). In order to determine whether the gonococci at that time prevailing in West London were more or less resistant to the action of kanamycin than those in other parts of London, it was decided to treat a number of cases of acute urethral gonorrhoea in male patients with a single intramuscular injection of $2 \mathrm{~g}$. kanamycin.

TREATMENT OF URETHRAL GONORRHOEA WITH 2 g. KANAMYCIN.

The series consisted of 35 patients. Their ages ranged from 19 to 36 years (mean of 27-8). 29 were United Kingdomborn, 5 West Indian, and one Australian. 32 were single, two married, and one was separated. Five acquired their infections from active homosexual practice. Fourteen (40 per cent.) gave past histories of venereal disease.

Results

Of the 35 cases treated, 32 were followed, and treatment failure was observed in one ( 3 per cent.).

\section{Comment}

The failure rate of 3 per cent. in cases of urethral gonorrhoea accords with the findings of Wilkinson, Race, and Curtis (1967), who reported a treatment failure rate of 2 to 3 per cent. 


\section{Discussion}

It has often been assumed in the past that the explanation for the poor performance of penicillin in the treatment of rectal gonorrhoea lies in the fact that the lower alimentary tract contains many microorganisms capable of producing penicillinase. This inactivates the penicillin reaching the lumen of the gut before it has time to exert much antibacterial action on the gonococci. The relatively disappointing showing of kanamycin in rectal infections vis-à-vis urethral infections suggests a possible alternative explanation: the function of the lower gut is so geared to the absorption of water from the lumen that the passage of any material in the reverse direction might require an impossibly high diffusion gradient. If this be the case, one of us (A.B.H.) suggests that local treatment might be preferable to systemic treatment in cases of rectal gonorrhoea.

\section{Summary}

The results of treating rectal gonorrhoea with either procaine penicillin 1.8 megaunits or kanamycin $2 \mathrm{~g}$. are presented. 100 cases were treated with each regime. Treatment failure was observed in 27.1 per cent. of those followed who received procaine penicillin and in 15.5 per cent. of those followed who received kanamycin $2 \mathrm{~g}$. The failure rate with kanamycin was higher than anticipated and to indicate whether this was due to resistance to kanamycin of the local strains of gonococci, 35 cases of urethral gonorrhoea were also treated with kanamycin $2 \mathrm{~g}$; the treatment failure rate in this series was 3 per cent. of those followed. It is suggested that the difficulty of treating rectal infections may be due to the fact that a very high diffusion gradient must exist between the rectal lumen and the bloodstream before diffusion can occur. In the opinion of one of us (A.B.H.), oral administration of a non- absorbed antibiotic or local therapy by means of enemata or suppositories may be preferable to systemic therapy.

\section{References}

Dallas, N. L. (1958) Brit. f. vener. Dis., 34, 194

Evans, A. J. (1966) Ibid., 42, 251

FINEGOLD, S. M. (1959) Arch. intern. Med., 104, 15

FlUKER, J. L. (1966) Brit. f. vener. Dis., 42, 48

HewitT, A. B. (1969) Ibid., 45, 40

Hooton, W. F., and Nicol, C. S. (1967) Postgrad. med. f., 43, Suppl., p. 68

JefFeriss, F. J. G. (1966) Brit. F. vener. Dis., 42, 46

Piguet, B. (1961) Ibid., 37, 244

Scott, J., and Stone, A. H. (1966) Ibid., 42, 103

Wilkinson, A. E., RACE, J. W., and Curtis, F. R. (1967) Postgrad. med. F., 43, Suppl. (May, 1967), 'The clinical aspects of kanamycin', p. 63

\section{La kanamycine dans le traitement de la gonococcie rectale \\ SOMMAIRE}

On expose les résultats du traitement de la gonococcie rectale soit avec 1,8 méga-unités de pénicilline-procaïne, soit avec $2 \mathrm{~g}$. de kanamycine. 100 cas furent traités dans chaque série. Le pourcentage des échecs sur les sujets suivis fut de 27,1 avec la pénicilline-procaïne et de 15,5 avec $2 \mathrm{~g}$. de kanamycine. Le taux des échecs avec la kanamycine fut plus élevé que prévu et, pour savoir si ceci n'était pas dû à la résistance à la kanamycine de souches locales de gonocoques, 35 cas de gonococcie urétrale furent également traités avec $2 \mathrm{~g}$. de kanamycine; le taux des échecs dans cette série fut de 3 pour cent des cas suivis. On suggère que la difficulté du traitement des infections rectales peut être dû au fait qu'il doit exister un haut coefficient de diffusion entre la lumière rectale et le courant sanguin avant que cette diffusion s'effectue. Selon l'avis de l'un de nous (A.B.H.) l'administration buccale d'un antibiotique non absorbable ou un traitement local par lavements ou suppositoires pourrait être préférable au traitement par voie générale. 